\title{
Comparative study on the agility and flexibility ability of state and national level male players between handball and volleyball of poonch district ( jammu and kashmir).
}

\author{
Neeraj Sharma ${ }^{1}$, Shafqit Hussain ${ }^{2}$ \\ ${ }^{1,2}$ (PET) Deptt. Of Youth Services and Sports Govt. Of J\&K India \\ Email:neeraj_sharma@gmail.com
}

\begin{abstract}
Sports, the most ancient human endeavour, known through ages since the time of Hercules, relates to various form of recreational activities like hunting, shooting, sailing,, outdoor games, athletics, swimming etc .Every society tries to include certain values in younger generation through the medium of sports. Ancient society want to encourage valour, dignity and loyalty to the group. Likewise modern society emphasizes specialization, professionalization and commercialization in the realm of sports also. In the present day scenario "Sports For all" has become a popular slogan all over world. Games and sports are is the specialised field. It requires a specific, scientific, and systematic type of training to increase optimum performance of the player. Each game requires different and specific type of physical fitness, components and training method to develop that components there are five physical fitness components and inter related to each other directly and indirectly each components has its own importance in different games and sports. Volleyball and Handball required flexibility and agility which influence the performance of the player and game. That is why the purpose of the study was to compare the flexibility and agility between the state and national level players of volleyball and handball of district Poonch( jammu and Kashmir) state. To collect data for this study, total 30 (No 30) subject were selected out of which fifteen(15) from Handball and fifteen from Volleyball discipline in District Poonch of J\&K State. The age of the subject were ranged from 15 to 20 years according to the school and college records. Flexibility and agility ability were selected as dependent variables for the study. Sit and reach test was used to measured flexibility and $10 * 4$ shuttle run test was used to measured agility of the players. These tests were administered after proper ground marking, proper demonstration and proper warming up of the players. The collected data were statistically analyzed for significant difference by using independent test. The level of significance was set at 0.05 .
\end{abstract}

Keywords: Volleyball, Handball, Agility, Flexibility

\section{INTRODUCTION}

Sports, the most ancient human endeavour, known through ages since the time of Hercules, relates to various form of recreational activities like hunting, shooting, sailing,, outdoor games, athletics, swimming etc .In the present day scenario "Sports For all" has become a popular slogan all over world. It is a over expanding arena of human life. Sports is an experience that one can gain by participating is various social activities. It is well known saying that "Sound body resides in a sound body" so by participating in sports and by doing regular physical activity one can attain the optimum physical fitness and positive health which pre- requisite of a sound and healthy body. Participation in sports and regular physical activity will lead to optimum physical fitness, positive health impact, helps to keep the person physically and mentally fit, free from diseases and there is no need to visit the doctors, hospitalization and medication. Today sports become more popular in every corner of the world because modern sports are more scientific, well organised, directly health relates, benefits not only physically but mentally also, being honours and social dignity in national and international level for the successful participants..For optimum performance in the field of games and sports require comprehensive abilities including physical, technical, tactical, psychological etc. According to the requirement of the games like ball game volleyball to achieve 
optimum performance in national and international level. Players of both games also requires discipline, dedication, interest, to ability according to the demand of the game volleyball is the most popular game in the China, united states, Brazil, Japan, Russia most popular countries in the games of volleyball. Federation international de volleyball(FIVB) is governing body of volleyball in the world.

In India (VFI) volleyball federation of India governing body of volleyball in India and organises national championship in all age group, Federation cup, volleyball league, Pro volleyball etc. Hand ball is also very popular and fast game in the world. The international handball federation (IHF) is the administrative and controlling body of handball in the world level. In India(HFI) Handball Federation of India administrative and controlling body band organizes all the national level tournaments. Volleyball and Handball required flexibility and agility which influence the performance of the player and game. That is why it is necessary to compare of flexibility and agility between volleyball and handball players. Flexibility and agility play a very important role at the time of attacking, defending as well as blocking.

\section{REVIEW OF RELATED LITERATURE}

Shashikant Pardeshi and Dr. Govind Kadam (2016) A comparative study of physical fitness components between baseball and softball player of pune city. In this study they comparaed with physical fitness of both the groups and observed that both are not equal in physical fitness.

Jaskaran singh(2019) Studied that on the basis of statically analysed Handball players were more superior than basketball players as compared in strength ability. A comparative study of strength level among handball and basket ball male players.

Sandeep Chaudhary, Dr. Vandana verma (2018) A comparative study of selected physical fitness among university level hockey and football players;20-22 (2018). In this study auther find that no significant difference found in speed ability between hockey and football players and there was significant deference exist between hockey and football group and football were more agile than hockey group.

\section{Definition of the terms:-}

1. Flexbility:- It is the ability of joints to move in maximum range it is different from joint to joint due to its structure, surrounding, adjoining ligaments tendons and muscles.

2. Agility:- It is the ability of the body to perform movement with perfection and efficiency in other words we can say that it is the ability to change movement or direction in shortest time without getting unbalanced.

Need and importance of components of physical fitness:-

Games and sports are is the specialised field. It requires a specific, scientific, and systematic type of training to increase optimum performance of the player. Each game requires different and specific type of physical fitness, components and training method to develop that components there are five physical fitness components and inter related to each other directly and indirectly each components has its own importance in different games and sports. Such Physical components play a major role to improve the importance of the player. Without improving these physical component a player can not improve his/her performance in the field of games and sports.

Objective of the study:-

1. To find out the flexibility ability to volleyball and handball player.

2. To find out the agility ability to volleyball and handball player.

Statement of the Problem:- The purpose of the study was to compare the flexibility and agility between the state and national level players of volleyball and handball in jammu and Kashmir state.

\section{METHODOLOGY}

To collect data for this study, total 30 (No 30) subject were selected out of which fifteen(15) from Handball and fifteen from Volleyball discipline in District Poonch of J\&K State. The age of the subject were ranged from 15 to 20 years according to the school and college records. Flexibility and agility ability were selected as dependent variables for the study. Sit and reach test was used to measured flexibility and $10 * 4$ shuttle run test was used to measured agility of the players. These tests were administered after proper ground marking, proper demonstration and proper warming up of the players. 
Variables of the Test Showing in Table.

\begin{tabular}{|l|l|l|}
\hline Variables & Test & Units of measures \\
\hline Agility & Sit and Reach test & $\mathrm{Cm}$ \\
\hline Flexibility & Shuttle Run $\left(10^{*} 4\right)$ & Seconds \\
\hline
\end{tabular}

\section{STATISTICAL ANALYSIS}

The collected data were statistically analyzed for significant difference by using independent $t$ test. The level of significance was set at 0.05 . The finding of comparison between volleyball and Handball players, flexibility and agility ability was show in table.

Table 1:Comperative study of Agility test (10*4) shuttle run of Volleyball and Handball Players.

\begin{tabular}{|c|l|l|l|l|l|}
\hline variables & $\mathrm{N}$ & Groups & Mean & SD & T Value \\
\hline \multirow{2}{*}{ Agility } & 15 & Volleyball & 10.37 & 0.11 & 2.33 \\
\cline { 2 - 5 } & 15 & Handball & 10.07 & 0.47 & \\
\hline
\end{tabular}

Table 2: Comparative of study flexibility test ( sit and reach) of Volleyball and Handball Players.

\begin{tabular}{|c|l|l|l|l|l|}
\hline variables & $\mathrm{N}$ & Groups & Mean & SD & T Value \\
\hline \multirow{2}{*}{ Flexibility } & 15 & Volleyball & 25.33 & 3.83 & 3.27 \\
\cline { 2 - 5 } & 15 & Handball & 31.27 & 5.60 & \\
\hline
\end{tabular}

Tale 1. show that the mean of agility of volleyball ad handball players is 10.37 and 10.07 respectively. Whereas the standard deviation of the agility of volleyball ad handball players is 0.11 ad 0.47 respectively. The $\mathrm{t}$ value is 2.33 . The result show that there is significant difference exist in agility between volleyball ad handball players. Handball players were found better in agility as compare to volleyball players.

Tale 2. show that the mean of agility of volleyball ad handball players is 25.33 and 31.27 respectively. Whereas the standard deviation of the agility of volleyball ad handball players is 3.83 and 5.60 respectively. The $\mathrm{t}$ value is 3.27 . The result show that there is significant difference exist in agility between volleyball ad handball players. Handball players were found better in agility as compare to volleyball players.

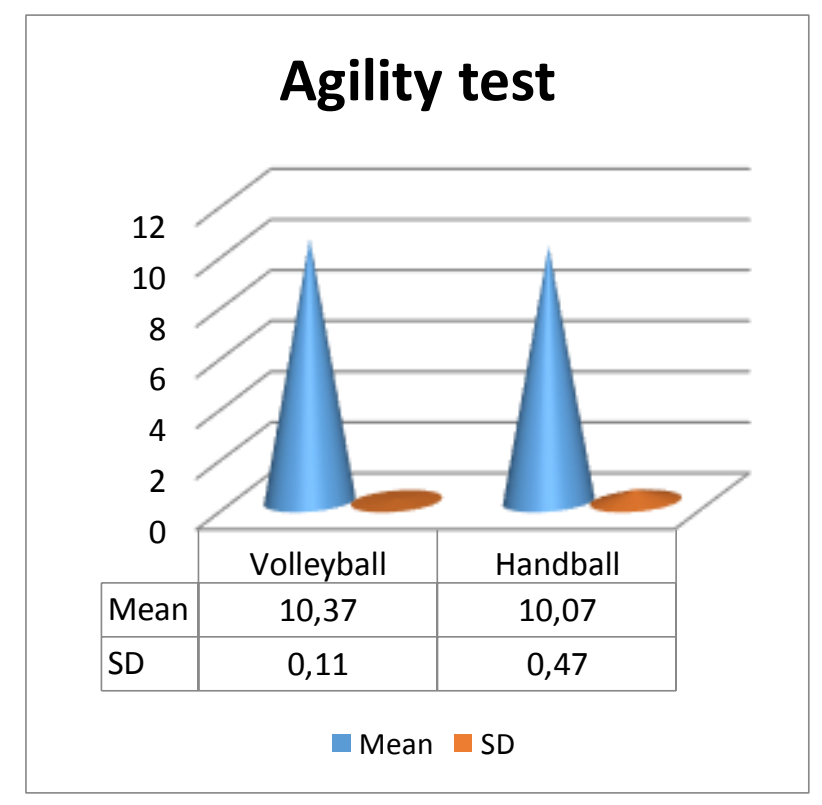

Graph No 1 


\section{Flexibility test}

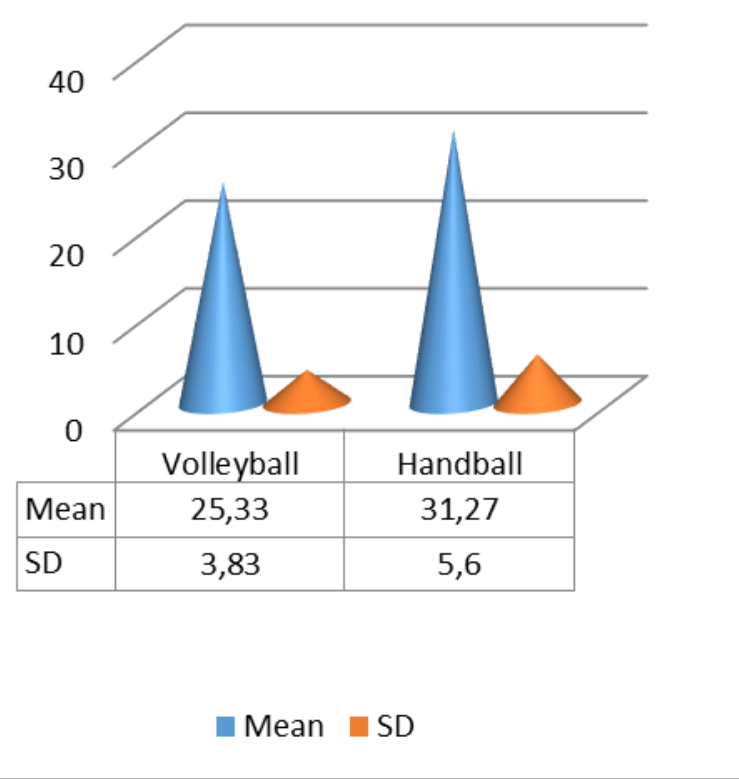

Graph No 2

\section{DISCUSSION}

Obtained result of the study show that there is significant difference exist between volleyball ad handball players as for as agility and flexibility is concern. Handball players were found better in agility and flexibility as compared to volleyball players. Many studies has shown similar type of result. But in this study the state and national level volleyball players of district pooch (Jammu and Kashmir) need to improvement in physical fitness components especially agility and flexibility.

\section{CONCLUSION}

Significant difference exist between volleyball and handball players as for as agility and flexibility is concerned. Handball players were found better in agility and flexibility as compared to volleyball players. The purpose of the study was to evaluate the group difference between state and national level players of Handball and Volleyball in agility and flexibility of male players of district poonch ( Jammu and Kashmir). Agility and flexibility play a vital role to influence the performance of both games like volleyball ad handball. Further investigations are needed on the above studied variables along with physiological variables to assess relationship among them and with performance in volleyball and handball players.

\section{REFERENCES}

1. Shashikant Pardeshi and Dr. Govind Kadam (2016) A comparative study of physical fitness components between baseball and softball player of pune city.I nternational journal of Physiology, Nutrition and Physical Education; 1(2) :218-219.

2. Jaskaran singh(2019) Studied that on the basis of statically analysed Handball players were more superior than basketball players as compared in strength ability. A comparative study of strength level among handball and basket ball male players.

3. Sandeep Chaudhary, Dr. Vandana verma (2018) A comparative study of selected physical fitness among university level hockey and football players;20-22 ( 2018). A international journal of physical education and sports.

4. Sigh, j 2013. Comparison of motor fitness components among different games players. .International journal of Movement Education and Social Sciece,1,51-56. 
5. Vikram sigh et al. Comparison of Selected Motor fitness Variables among male basketball, volleyball and handball players human kinetics journal of physical education.2010;1(2):44-49.

6. Ghosh SS.A comparative Study on physical fitness among state level footballers and volleyball players. Indian journal of Applied Research, 2013;3(8):66-68.

7. Uppal AK, Roy P. Assessment of motor Fitness Components as predictors of soccer playing ability. SNIPES journal. 1989;9(3):46-49.

8. Trikha S. Comparative status of strength and speed between different team games. Global Journal for research analysis. $2014 ; 3(7): 253$.

9. Nixon JE, Jeweet AE, Nixon EW. A introduction of physical education. Philadelphia: W,B, Saunders Company, 1969,196. 